\title{
Using a Dermis Fat Graft for Volumetric Rejuvenation of Deep Superior Sulcus in the Eyelid Due to an Anophthalmic Socket
}

\author{
(D) Mehmet Serhat Mangan
}

University of Health Sciences, Haydarpasa Numune Education and Research Hospital, Sadik Eratik Eye Institute, Division of Oculoplastic and Reconstructive Surgery, Istanbul, Turkey

\section{Abstract}

Enophthalmos, shallow fornices, and deep superior sulci in the eyelids may be encountered in patients with an anophthalmic socket due to gradual fibrosis of orbital tissues. Herein, a 42-year-old woman presented to our clinic due to dissatisfaction with the sunken appearance of her right upper eyelid. She had undergone evisceration surgery in the past and had been using a prosthesis in the right eye for the last 30 years. Moreover, ophthalmologic examination revealed a deep superior sulcus deformity of the right eyelid. A dermis fat graft was placed and volumetric correction of the right upper eyelid sulcus deformity was performed, which resulted in significant rejuvenation of the upper eyelid sulcus deformity on postoperative follow-up. In conclusion, dermis fat grafts can be used as a safe alternative method for volumetric correction of intraconal or extraconal volume loss that develops in patients with an anophthalmic socket.

Keywords: Anophthalmic socket, dermis fat graft, periorbital rejuvenation, deep superior sulcus, sunken eyelid

\section{INTRODUCTION}

Patients with an anophthalmic socket may develop enophthalmos, shallow fornices, and deep upper eyelid sulci due to gradual fibrosis of orbital tissues (1). As a result, dermis fat grafts have been utilized to correct enophthalmos and repair eyelid volume loss (2-7). The usage of dermis fat grafts is especially significant in patients with an anophthalmic socket, since deep upper eyelid sulcus deformities can negatively impact their appearance, causing cosmetic concerns. Therefore, in this case report, we present the surgical repair of a deep sulcus deformity in the upper eyelid due to an anophthalmic socket using dermis fat grafting.

\section{CASE PRESENTATION}

Written informed consent was obtained from the patient for the publication of this case report and any accompanying images. This case report follows the ethical principles outlined in the Declaration of Helsinki.
A 42-year-old woman presented to our clinic due to dissatisfaction with the sunken appearance of her right upper eyelid. She had a previous history of evisceration surgery and had been using an ocular prosthesis for 30 years since then. Ophthalmologic examination revealed a deep sulcus deformity of the right upper eyelid (Figure 1a). There was an implant in the orbit, and no pathology was observed in the anophthalmic socket. Thus, she was recommended rejuvenation of the upper eyelid sulcus deformity using a dermis fat graft. Under general anesthesia, the upper eyelid crease was marked using a sterile marking pen. Then, 3 cc of a local anesthetic solution (2\% lidocaine with 1:100,000 epinephrine, diluted half with saline) was injected along the eyelid crease. Next, a skin incision in the upper eyelid crease was made using a Westcott scissor,and the orbicularis muscle and orbital septum were opened (Figure 1b). Afterward, the preaponeurotic fat was identified and exposed. The periosteum overlaying the superior orbital rim was dissected, and the atrophic area in the superior-nasal and superior-temporal orbital regions was observed (Figure 1c). 
The horizontal size of the eyelid skin incision was measured. Then, the superolateral quadrant of the gluteal region was marked using the marking pen. Approximately 2 cc of the local anesthetic solution (2\% lidocaine with 1:100,000 epinephrine, diluted half with saline) was injected, and a $2 \times 1 \times 0.5 \mathrm{~cm}$ dermis fat graft was harvested from the gluteal region (Figure 1d, 2a). Since postoperative atrophy can be observed in the dermis fat graft, the graft harvested was roughly $30 \%$ larger than the orbital defect. The size of the harvested graft can vary depending on the surgeon's preference (7). The donor site was then repaired with primary closure using 3-0 polyglactin sutures. The epidermal layer of the harvested graft was excised in order to ensure better vascularization of the graft in the recipient bed and to prevent possible cyst formation.

Following excision, the dermis fat graft was placed in the atrophic area, with the dermis part facing anteriorly and the fat part posteriorly (Figure 2b). The superior border of the dermis fat graft was anchored in place to the superior orbital rim using 6-0 polyglactin sutures. The graft was then trimmed to fit the available space, and the superior sulcus deformity was observed to significantly improve (Figure 2c). Then, the upper eyelid crease was reformed using 6-0 polyglactin sutures and the skin incision was closed. Follow-up examination on postoperative day 10 showed further significant improvement of the upper eyelid sulcus deformity (Figure 2d).

\section{DISCUSSION}

An optimum anophthalmic socket is required for ideal positioning of an ocular prosthesis. Anophthalmic sockets can develop various complications, including discharge, infection, entropion, ectropion, conjunctival cysts, orbital implant exposure or extrusion, orbital implant migration, contracted socket, and ptosis (1-9). Moreover, the mechanical impact of the prosthetic eye can lead to gradual volume loss in orbital tissues, which affects the positioning of a prosthesis and consequently increases the risk of complications (1).

In ophthalmology, volume augmentation in the anophthalmic socket is among the most common areas of use for dermis fat grafts (1-5). These grafts, in particular, can be used to repair volume deficits in the upper and lower eyelids. While they can be placed in the intraconal space, they can also be preferred for enophthalmos that may occur after orbital fracture repair (1-5). Additionally, these grafts can increase cosmetic satisfaction in functioning eyes and improve functional outcomes in individuals
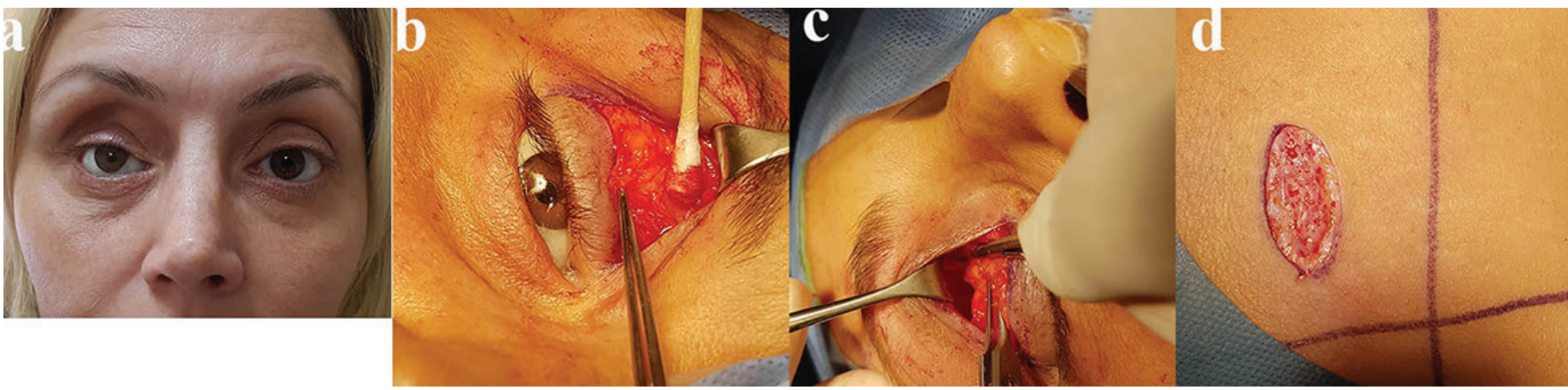

Figure 1. (a) Deep sulcus deformity in the right upper eyelid preoperatively. (b) Opening of the orbital septum after upper eyelid crease incision. (c) View of the atrophic area in the superior-nasal and superior-temporal orbital regions. (d) Dermis fat graft incision from the superior-lateral quadrant of the gluteal region
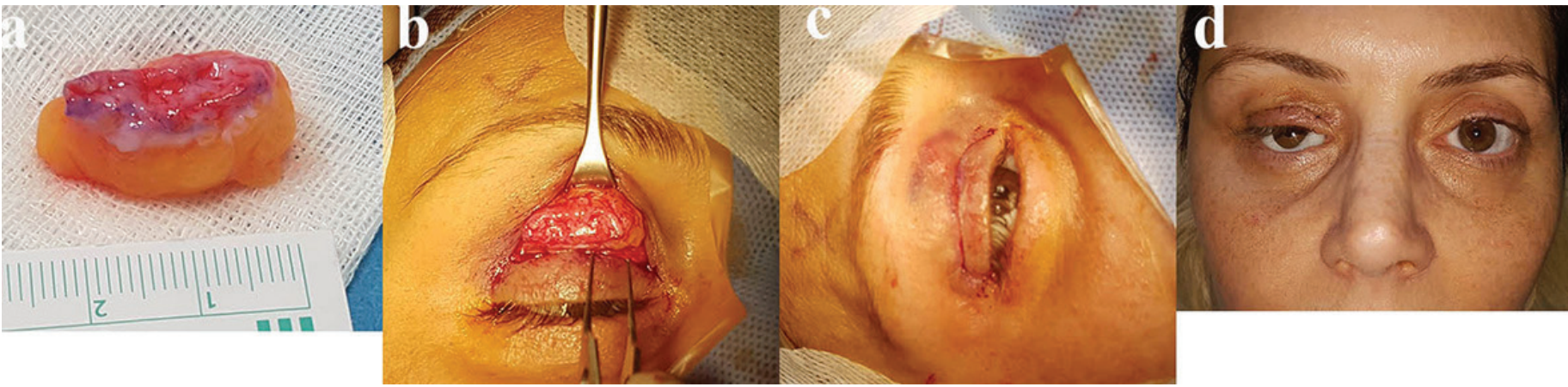

Figure 2. (a) View of the $2 \times 1 \times 0.5 \mathrm{~cm}$ dermis fat graft. (b) Dermis fat graft was placed in the atrophic area, with the dermis part facing anteriorly and the fat part posteriorly. (c) View of the last step of surgery after dermis fat graft implantation in which the superior sulcus deformity improves significantly. (d) Follow-up examination on postoperative day 10 showed significant improvement of the upper eyelid sulcus deformity 
with ocular prosthesis. Unlike non-autologous materials, one of its greatest advantages is that dermis fat grafts possess no risk of rejection. However, these grafts have a disadvantage of up to $50 \%$ risk of graft resorption in the long-term. Furthermore, postoperative complications, including transient supraorbital neuropraxia, liquefied fat discharge from the skin incision, infection, and abscess formation, have been reported in literature (5).

Volume loss in the anophthalmic socket can be intraconal and/ or extraconal. Specifically, intraconal volume loss usually leads to enophthalmos, whereas extraconal volume loss often leads to eyelid position problems (1-5). As presented in our case, dermis fat grafts can be utilized for treating deep superior sulcus deformities (5-7). Anchoring the dermis fat graft into the periosteum of the orbital rim can both expand volume and decrease scar tissue formation (5-7). Moreover, dermis fat grafting can cause early ptosis, which typically resolves over time with decreasing tissue edema and fat resorption, as presented in this case (5).

\section{CONCLUSION}

In conclusion, dermis fat grafting is an alternative and safe method that can be used to repair intraconal or extraconal volume loss occurring in patients with an anophthalmic socket.

\section{Ethics}

Informed Consent: Written informed consent was obtained from the patient for the publication of this case report and any accompanying images.
Peer-review: Externally and internally peer-reviewed.

Financial Disclosure: The author declared that this study received no financial support.

\section{REFERENCES}

1. Aryasit $\mathrm{O}$, Preechawai P. Indications and results in anophthalmic socket reconstruction using dermis-fat graft. Clin Ophthalmol 2015;9:795-9.

2. Çoban Karataş M, Altan Yaycıoğlu R, Canan H. Orbital Dermis Yağ Greft Implantasyonu: Primer ve Sekonder İmplant Sonuçları. Turk J Ophthalmol 2015;45:65-70.

3. Sendul SY, Dirim B, Atılgan CU, Demir M, Demir ST, Olgun A, et al. Prosthesis-socket volume imbalance and dermofat graft rehabilitation in patients with an anophthalmic socket. Arq Bras Oftalmol 2020;83:338.

4. Modugno AC, Resti AG, Mazzone G, Moretti C, Terreni MR, Albanese G, et al. Long-term outcomes after cosmetic customized prostheses and dermis fat graft in congenital anophthalmia: a retrospective multicentre study. Eye (Lond) 2018;32:1803-10.

5. Rose GE, Collin R. Dermofat grafts to the extraconal orbital space. $\mathrm{Br}$ J Ophthalmol 1992;76:408-11

6. Proffer PL, Czyz CN, Cahill KV, Kavanagh MC, Everman KR, Burns JA, et al. Addition of dermis-fat graft to diminish cable visibility in frontalis suspension for patients with pre-existing deep superior sulci. Ophthalmic Plast Reconstr Surg 2009;25:94-8.

7. Czyz CN, Foster JA, Wulc AE. Superior Sulcus Volumetric Rejuvenation Utilizing Dermis Fat Grafting. Aesthet Surg J 2015;35:892-8.

8. Palamar Onay M, Ceylan N, Yağ cl A. Anoftalmik Sokette Gelișen Konjonktiva Kisti Tedavisinde Trikloroasetik Asit Enjeksiyonu. Turk J Ophthalmol 2011;41:389-91.

9. Taner P, Yazici B, Akarsu C, Demirbas E, Ergin A. Anoftalmik Sokette Bakteri Kolonizasyonu. Turk J Ophthalmol 2003;33:484-7. 